\title{
Oxidative/Nitrosative Stress and Protein Damages in Aqueous Humor of Hyperglycemic Rabbits: Effects of Two Oral Antidiabetics, Pioglitazone and Repaglinide
}

\author{
Anna Gumieniczek, Beata Owczarek, and Bernadeta Pawlikowska \\ Department of Medicinal Chemistry, Medical University of Lublin, Jaczewskiego 4, 20-090 Lublin, Poland \\ Correspondence should be addressed to Anna Gumieniczek, anna.gumieniczek@umlub.pl
}

Received 14 October 2011; Revised 28 December 2011; Accepted 29 December 2011

Academic Editor: Pietro Galassetti

Copyright (C) 2012 Anna Gumieniczek et al. This is an open access article distributed under the Creative Commons Attribution License, which permits unrestricted use, distribution, and reproduction in any medium, provided the original work is properly cited.

The present study was undertaken to determine oxidative/nitrosative stress in aqueous humor of alloxan-induced hyperglycemic rabbits and to investigate the effects of two oral antidiabetic drugs, pioglitazone from peroxisome proliferator-activated receptor gamma (PPAR $\gamma$ ) agonists and repaglinide from nonsulfonylurea $\mathrm{K}_{\mathrm{ATP}}$ channel blockers. Ascorbic acid (AA), glutathione (GSH), total antioxidant status (TAS), lipid peroxidation products (LPO), total nitrites $\left(\mathrm{NO}_{2}\right)$, advanced oxidized protein products (AOPP), and protein carbonyl groups (PCG) were determined using respective colorimetric and ELISA methods. In our hyperglycemic animals, AA decreased by $77 \%$, GSH by $45 \%$, and TAS by $66 \%$ as compared to control animals. Simultaneously, LPO increased by $78 \%$, PCG by $60 \%$, AOPP by $84 \%$, and $\mathrm{NO}_{2}$ by $70 \%$. In pioglitazone-treated animals, AA and TAS increased

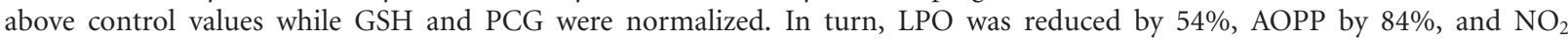
by $24 \%$, in relation to hyperglycemic rabbits. With repaglinide, AA and TAS were normalized, GSH increased by $20 \%$, while LPO decreased by $45 \%$. Our results show that pioglitazone and repaglinide differ significantly in their ability to ameliorate the parameters like $\mathrm{NO}_{2}$, PCG, and AOPP. In this area, the multimodal action of pioglitazone as PPAR $\gamma$ agonist is probably essential.

\section{Introduction}

The eye is a unique organ since it is constantly exposed to radiation, atmospheric oxygen, environmental chemicals, and physical abrasion. In consequence, the eye provides a unique situation for generation of reactive oxygen species (ROS). In particular, oxidative stress is implicated in the etiology of many ocular diseases such as glaucoma, retinal degeneration, ocular inflammation, cataracts, and diabetic complications [1-3]. Also nitrogen reactive species (RNS) play an important role in different oxidative alterations $[4,5]$. Nitric oxide (NO) is an important messenger in vascular and nervous systems or in immunological reactions including these in the eye. On the other hand, NO formed in excess by inducible NO synthase (iNOS) may cause serious ocular injuries [6].
Ocular tissues and fluids contain antioxidants that play a key role in protecting them against these oxidative/nitrosative damages. Aqueous and vitreous humors as well as lens contain high amounts of ascorbic acid (AA). It is generally accepted that it offers significant protection for the eye by suppressing generation of free radicals [7]. Also ocular glutathione $(\mathrm{GSH})$ participates in neutralization of reactive species and maintains other antioxidants in their active forms. Unfortunately, these antioxidants are not able to eliminate free radicals completely and if oxidative stress is severe, it may cause cell damage or death [3].

Protein carbonyls groups (PCG), markers of early protein oxidation, and advanced oxidized protein products (AOPP) have been recently described as closely related to different pathological situations [8-10]. Some findings also suggest 
that the changes in proteins may be important in development of ocular diabetic complications [11].

Therefore, the present study was undertaken to determine several markers of oxidative/nitrosative stress in aqueous humor of alloxan-induced hyperglycemic rabbits where such experiments have not been performed previously. We wanted to explore potent relationship between some commonly studied parameters of oxidative alterations: AA, GSH, total antioxidant status (TAS), lipid peroxidation products (LPO), total nitrites $\left(\mathrm{NO}_{2}\right)$, and two markers of oxidative protein modification, PCG and AOPP, and search for this which showed more expressive correlations.

It is known that structures through which aqueous humor leaves the anterior chamber may be a target of pharmacological manipulations. Thus, reducing ROS/RNS overproduction and its consequences may be an effective strategy for protection against severe ocular injuries [11, 12]. Therefore, the second goal of the present study was to investigate which of two oral antidiabetic drugs, a peroxisome proliferator-activated receptor gamma (PPAR $\gamma)$ agonist pioglitazone or a nonsulfonylurea $\mathrm{K}_{\mathrm{ATP}}$ channel blocker repaglinide could be more effective in ameliorating these oxidative/nitrosative changes. Pioglitazone belonging chemically to 2,4-thiazolidinediones family (TZDs) acts in diabetes mainly by decreasing insulin resistance at the level of the muscle and liver. It has been shown to be potent antioxidant in different pathological situations connected with oxidative/ nitrosative stress including diabetes [13, 14]. Repaglinide, from nonsulfonylurea $\mathrm{K}_{\mathrm{ATP}}$ channel blockers, is a carbamoyl methyl benzoic acid derivative with the effect on early insulin secretion and reducing postprandial glucose directly [15]. Additionally, some results from the literature have previously demonstrated that it may have positive effects on parameters of oxidative/nitrosative stress [16, 17].

\section{Material and Methods}

2.1. Animals and Chemicals. White male New Zealand rabbits (the mean weight $3.1 \mathrm{~kg}$ ) were housed in a controlled environment with $12 \mathrm{~h}$ light and dark cycles. They were provided with standard diet and water ad libitum. Animal care was in accordance with the "Principles of Laboratory Animal Care" (NIH publication No. 86-23, revised 1985) and with the Guidelines of Medical University of Lublin Animal Ethics Committee. The rabbits were divided into six groups of 5 animals: normal control (Group C), control treated with pioglitazone (Group $\mathrm{CP}$ ), control treated with repaglinide (Group CR), hyperglycemic (Group H), hyperglycemic treated with pioglitazone (Group HP), and hyperglycemic treated with repaglinide (Group HR). Hyperglycemia was induced by a single intravenous injection of $80 \mathrm{mg} / \mathrm{kg}$ of alloxan. Two weeks after the injection when hyperglycemia was verified by blood glucose concentration higher than $11 \mathrm{mmol} / \mathrm{L}$, administration of pioglitazone at a dose of $1 \mathrm{mg} / \mathrm{kg}$ and repaglinide at a dose of $0.3 \mathrm{mg} / \mathrm{kg}$ was started and continued for 4 weeks (the start of experiment). The drugs were given directly to oral cavity using a syringe without a needle, every day before the morning feeding.
During experiment, glucose concentration was monitored once a week. At the end of experiment, the animals were sacrificed with pentobarbital sodium at a dose of $60 \mathrm{mg} / \mathrm{kg}$. The aqueous humor was collected by a $26-\mathrm{G}$ needle attached to a tuberculin syringe with special care to avoid blood contamination. The needle was introduced into anterior chamber and ca. $100 \mu \mathrm{L}$ aqueous humor was withdrawn. The samples were stored at $-70^{\circ} \mathrm{C}$ until analysis.

TAS was assessed using a commercially available test from Randox Laboratories Ltd. (UK) while AA estimation was performed according to Kyaw [18]. GSH and LPO were determined using Bioxytech GSH-400 and LPO-586 kits from Oxis Research (USA). The stable metabolites of NO were estimated using a Nitrate/Nitrite Assay Kit from Fluka Chemicals (UK). Nitrates were reduced to nitrites by incubation of each sample for $120 \mathrm{~min}$ in the presence of nitrate reductase and NADPH. Then, total nitrites were assayed by adding of Griess reagent and measuring the absorbance at $540 \mathrm{~nm}$. PCG and AOPP levels were determined using respective ELISA or colorimetric kits from Immundiagnostik AG (Germany). Protein content was determined by the method of Lowry et al. [19] using bovine serum albumin as standard.

Two spectrophotometers, UV-Vis CE-6000 from CECIL Instruments (UK) and a Microplate Reader PowerWave XS from Bio-Tek Instruments Inc. (USA), were used.

2.2. Statistical Analysis. All numerical data are presented as the mean with respective standard error (SEM). The significance of differences was determined with Kruskal-Wallis and Mann-Whitney's $U$ tests. Multiple regression and Spearman's rank coefficients were used to investigate the possible correlations between AOPP or PCG level and other parameters. Probability $P$ less than 0.05 were considered significant. For all statistical evaluation, statistica software was used.

\section{Results}

In hyperglycemic animals, there were decreases of AA by $77 \%$, GSH by $45 \%$, and TAS by $66 \%$ as compared to control animals. Simultaneously, there were increases of LPO by $78 \%$, PCG by $60 \%$, AOPP by $84 \%$, and $\mathrm{NO}_{2}$ by $70 \%$. Pioglitazone increased AA and TAS above control values and normalized GSH and PCG. In turn, LPO was reduced by $54 \%, A O P P$ by $84 \%$ and $\mathrm{NO}_{2}$ by $24 \%$ in relation to hyperglycemic rabbits. With repaglinide treatment, AA and TAS were normalized while GSH increased by $20 \%$ and LPO decreased by $45 \%$ in relation to hyperglycemic rabbits. However, repaglinide did not affect the levels of PCG, AOPP, and $\mathrm{NO}_{2}$ (Table 1).

Multiple regression analysis did not show significant correlations. However, some correlations were observed when respective pairs of parameters were taken into account. In hyperglycemic group, we observed a negative correlation between AOPP and GSH, and positive correlations in pairs AOPP-LPO and AOPP- $\mathrm{NO}_{2}$ (Figures $1(\mathrm{a})-1(\mathrm{c})$ ). In hyperglycemic pioglitazone-treated group, similar correlations were observed between AOPP and LPO, and AOPP and $\mathrm{NO}_{2}$. In the case of PCG, correlations for both hyperglycemic 
TABLE 1: Effects of pioglitazone and repaglinide on oxidative/nitrosative stress parameters in the aqueous humor of control and hyperglycemic rabbits.

\begin{tabular}{lcccccc}
\hline & Group C & Group CP & Group CR & Group H & Group HP & Group HR \\
\hline TAS $(\mathrm{mmol} / \mathrm{mL})$ & $1.99 \pm 0.10$ & $1.96 \pm 0.15$ & $1.90 \pm 0.15$ & $0.67 \pm 0.09^{\mathrm{a}}$ & $2.37 \pm 0.14^{\mathrm{a}, \mathrm{b}}$ & $1.56 \pm 0.15^{\mathrm{b}}$ \\
$\mathrm{AA}(\mu \mathrm{g} / \mathrm{mL})$ & $12.90 \pm 1.05$ & $13.94 \pm 0.93$ & $10.03 \pm 1.05$ & $3.02 \pm 0.38^{\mathrm{a}}$ & $21.87 \pm 1.18^{\mathrm{a}, \mathrm{b}}$ & $12.62 \pm 1.36^{\mathrm{b}}$ \\
$\mathrm{GSH}(\mathrm{nmol} / \mathrm{mL})$ & $138.7 \pm 4.49$ & $144.2 \pm 12.84$ & $117.7 \pm 3.32^{\mathrm{a}}$ & $76.14 \pm 6.56^{\mathrm{a}}$ & $131.4 \pm 5.86^{\mathrm{b}}$ & $91.06 \pm 8.17^{\mathrm{a}, \mathrm{b}}$ \\
$\mathrm{NO}_{2}(\mathrm{nmol} / \mathrm{mL})$ & $39.04 \pm 2.84$ & $43.67 \pm 4.09$ & $37.44 \pm 2.5$ & $113.4 \pm 7.63^{\mathrm{a}}$ & $102.0 \pm 8.78^{\mathrm{a}}$ & $142.5 \pm 2.54^{\mathrm{a}}$ \\
LPO $(\mathrm{nmol} / \mathrm{mL})$ & $0.57 \pm 0.27$ & $0.89 \pm 0.25$ & $0.68 \pm 0.023$ & $2.64 \pm 0.14^{\mathrm{a}}$ & $1.21 \pm 0.11^{\mathrm{a}, \mathrm{b}}$ & $1.45 \pm 0.17^{\mathrm{a}, \mathrm{b}}$ \\
PCG $(\mathrm{nmol} / \mathrm{mg}$ protein $)$ & $17.86 \pm 1.36$ & $16.98 \pm 1.30$ & $24.13 \pm 1.63^{\mathrm{a}}$ & $44.49 \pm 2.15^{\mathrm{a}}$ & $20.46 \pm 2.96^{\mathrm{b}}$ & $40.46 \pm 3.57^{\mathrm{a}}$ \\
AOPP $(\mathrm{nmol} / \mathrm{mg}$ protein $)$ & $2.53 \pm 0.26$ & $2.44 \pm 0.26$ & $2.76 \pm 0.32$ & $16.15 \pm 2.24^{\mathrm{a}}$ & $4.31 \pm 0.18^{\mathrm{a}, \mathrm{b}}$ & $19.29 \pm 0.88^{\mathrm{a}, \mathrm{b}}$ \\
\hline
\end{tabular}

Values are mean \pm SEM $(n=5)$. TAS: total antioxidant status, AA: ascorbic acid, GSH: glutathione, $\mathrm{NO}_{2}$ : total nitrites, PCG: protein carbonyls, AOPP: advanced oxidized protein products. C: control rabbits, CP: control rabbits treated with pioglitazone, CR: control rabbits treated with repaglinide, H:

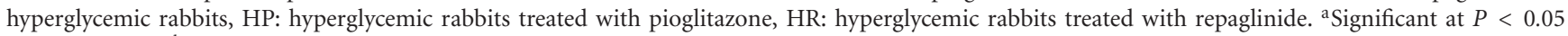

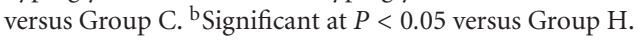

and hyperglycemic pioglitazone-treated animals were also significant, although respective $\mathrm{r}$ values were lower than these for AOPP (Figures 1(d) and 1(e)). Because repaglinide did not affect the altered protein oxidation, in this case respective correlations were not calculated.

\section{Discussion}

In the eye of diabetic subjects, the occurrence of oxidative stress was demonstrated as depletion of GSH, an important aqueous antioxidant [20]. Between others, GSH maintains the second major antioxidant AA in its active form [21]. Relation between these two antioxidants was confirmed in the present study where diminished levels of GSH and AA were stated in aqueous humor of our hyperglycemic animals. Some reports suggest that intracellular GSH level may be decreased by RNS derived from NO produced in excess by iNOS. As a consequence, production of nitrosoglutathione and formation of protein-mixed disulfides with glutathione have been reported [22]. Previously, excessive levels of NO were stated in vitreous fluid of patients with proliferative diabetic retinopathy [6]. It was also observed in the present study together with a decreased level of GSH. The altered antioxidant balance in aqueous humor of our hyperglycemic rabbits was additionally confirmed by a significant increase in lipid peroxidation. Previously, elevated concentrations of LPO were stated in vitreous fluid of diabetic $\mathrm{db} / \mathrm{db}$ mice [23] and in aqueous fluid of glaucoma patients [20].

Under situation of oxidative stress, many attention is devoted to oxidative damages in proteins [24]. They may result, between others, from formation of different protein adducts. Early modifications often bring carbonyl groups to proteins and may be estimated as 2,4-dinitrophenylhydrazine derivatives or PCG [25]. Recently, a large interest lies on latter products of protein oxidation (AOPP) which are defined as dityrosine-containing cross-linked protein products $[10,26]$. In aqueous humor of our hyperglycemic animals, the both markers, PCG and AOPP, were elevated in comparison with respective controls. Previously, similar changes were found in plasma of type 2 diabetic patients where higher increase in the level of AOPP compared with PCG was found. It was explained by lower susceptibility of AOPP cross-linked proteins to proteolysis and their subsequent accumulation in plasma [10]. In the present study, we additionally concluded that AOPP correlated better than PCG to other examined parameters (Figure 1).

In our study AA, TAS, GSH, and LPO were ameliorated by the two drugs, pioglitazone and repaglinide. However, only after pioglitazone, significant changes in $\mathrm{NO}_{2}, \mathrm{PCG}$, and AOPP were observed. It is known that AOPP are formed by action of chloraminated oxidants, mainly hypochlorous acid and chloramines, produced by myeloperoxidase (MPO) $[26,27]$. On the other hand, it has been showed that pioglitazone inhibits proinflammatory factors including MPO. Therefore, its present effect on AOPP in aqueous humor of hyperglycemic animals may be, at least in part, a consequence of the above ability.

It is known that expression of many genes including proinflammatory cytokines, adhesion molecules, and others such as iNOS was regulated by a nuclear factor NF- $\kappa$ B. It is also supposed that beneficial effects of antioxidants against oxidative complications may involve effective inhibition of NF- $\kappa$ B [6]. Such mechanism for antioxidative and anti-inflammatory properties of PPAR $\gamma$ agonists, including pioglitazone, has been proposed [28-30]. Previous data about decreased levels of $\mathrm{NO}_{2}$ and MPO after pioglitazone in lung and testis of our hyperglycemic animals confirm this $[31,32]$. However, the exact mechanism whereby the drug exerts its antioxidant effect is still unclear. In this area, the multimodal action of PPAR $\gamma$ agonists is probably essential [33].

As far as concerning $\mathrm{K}_{\mathrm{ATP}}$ channel blockers, it cannot be excluded that they may affect oxidative/nitrosative stress. After repaglinide, total serum antioxidant capacity [17] and lipid peroxidation were ameliorated $[15,16]$. After another drug mitiglinide, significant decreases of lipid peroxidation and nitrotyrosine were also observed [34]. However, all these effects occurred in type 2 diabetes where they could be probable by better controlling postprandial hyperglycemia and thus by the cluster of oxidative stress. Additionally, it has been stated that insulin per se reduces the level of NF- $\kappa$ B. Because NF- $\kappa$ B regulates the expression of enzymes involved in ROS/RNS generation, in this way, insulin can modulate the mechanisms involved in oxidative/nitrosative 


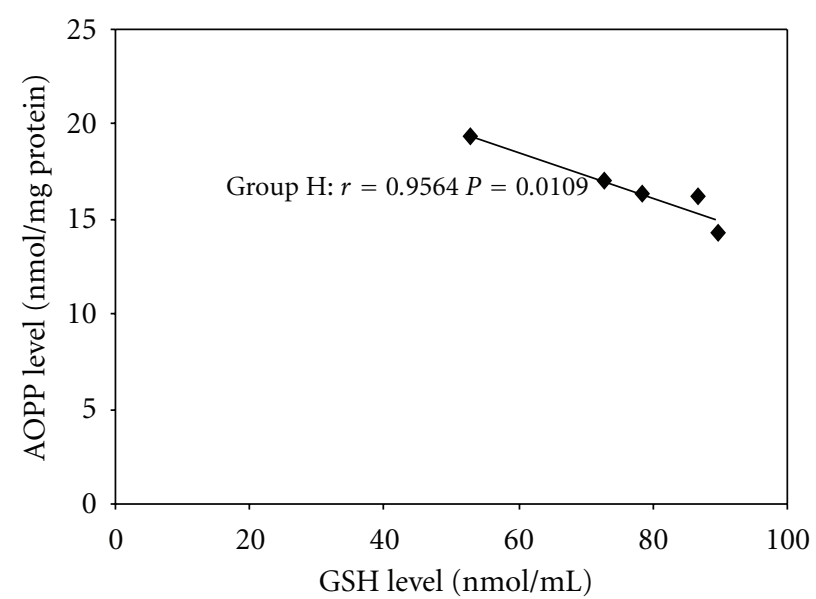

(a)

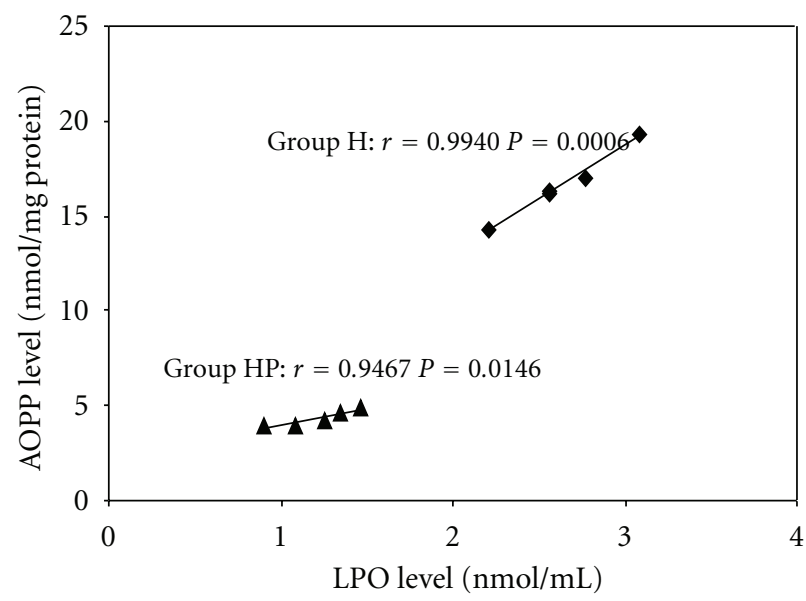

(b)

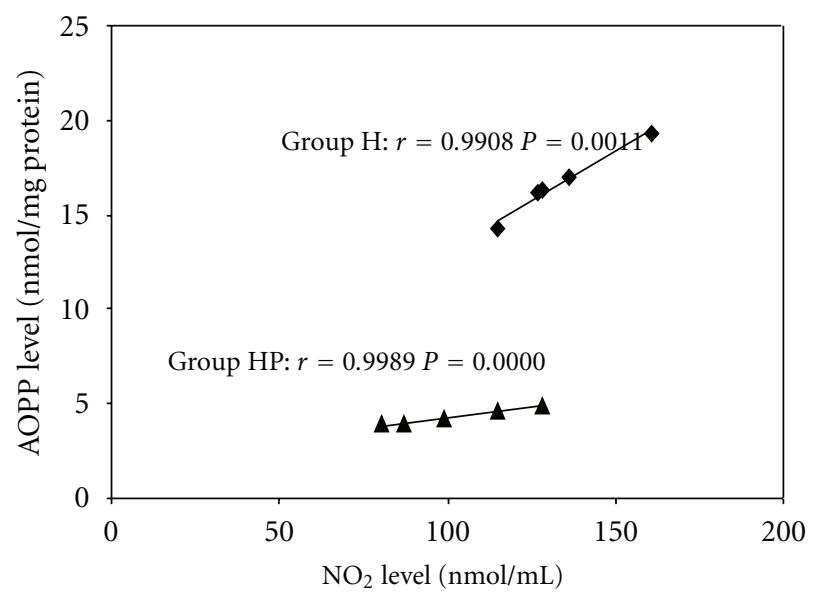

(c)

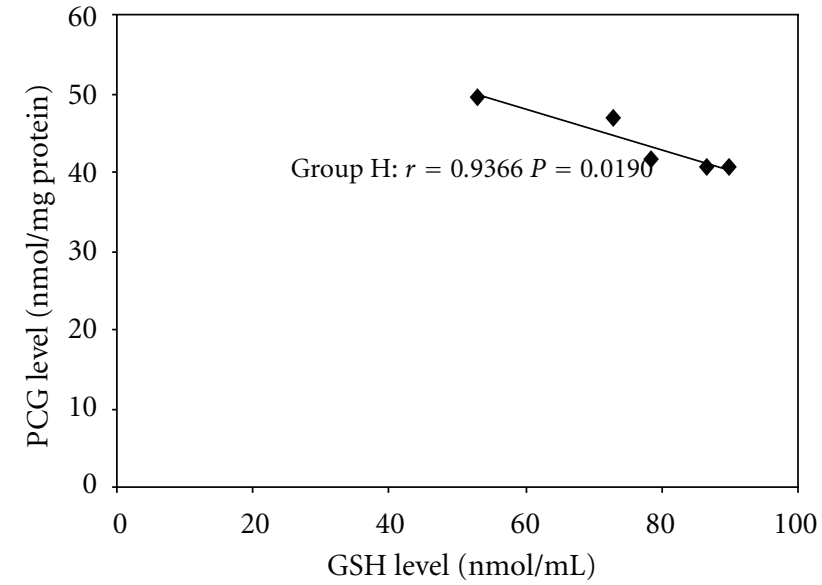

(d)

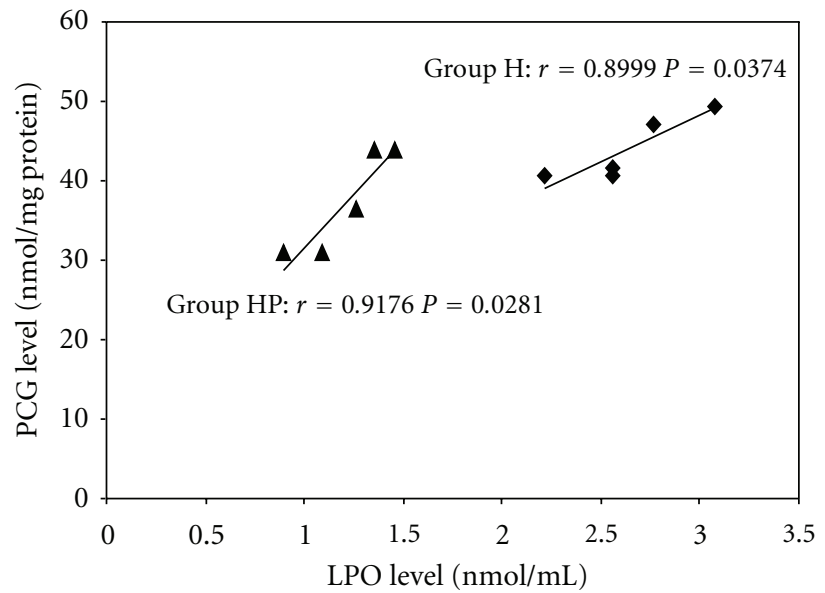

(e)

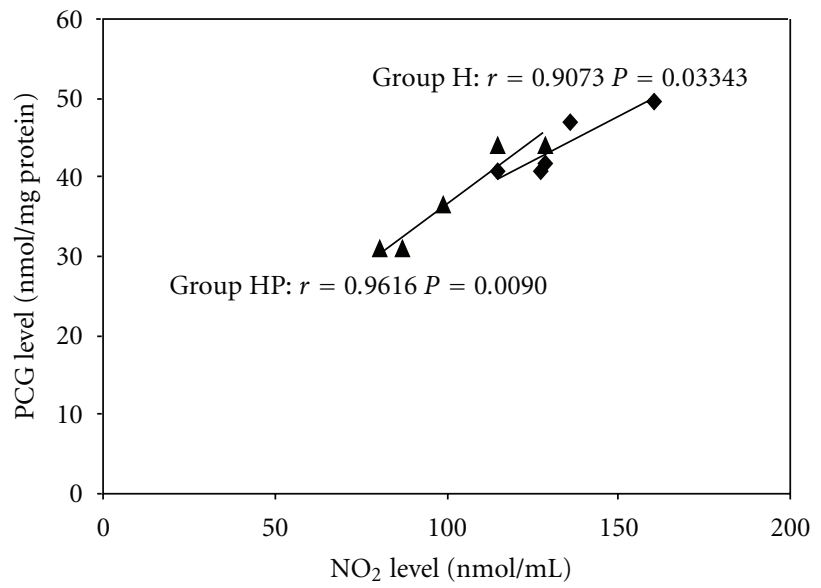

(f)

Figure 1: Correlations between GSH, LPO, and $\mathrm{NO}_{2}$ and respective protein oxidation marker, AOPP ((a)-(c)) or PCG ((d)-(f)), in hyperglycemic (Group H) and hyperglycemic pioglitazone-treated (Group HP) animals. 
TABLE 2: Blood glucose and plasma insulin concentrations in control and hyperglycemic rabbits at the start and the end of experiment.

\begin{tabular}{|c|c|c|c|c|}
\hline \multirow{2}{*}{ Group } & \multicolumn{2}{|c|}{ Glucose (mmol/L) } & \multicolumn{2}{|c|}{ Insulin (mU/L) } \\
\hline & Start & End & Start & End \\
\hline Control (C) & $6.2 \pm 0.1$ & $5.7 \pm 0.3$ & $13.16 \pm 1.26$ & $13.30 \pm 1.12$ \\
\hline Control-pioglitazone (CP) & $6.5 \pm 0.3$ & $5.9 \pm 0.3^{\mathrm{b}}$ & $11.74 \pm 0.72$ & $14.12 \pm 0.98^{\mathrm{b}}$ \\
\hline Control-repaglinide (CR) & $6.3 \pm 0.2$ & $4.0 \pm 0.3^{\mathrm{a}, \mathrm{b}, *}$ & $12.83 \pm 1.01$ & $20.0 \pm 1.42^{\mathrm{a}, \mathrm{b}, *}$ \\
\hline Hyperglycemic $(\mathrm{H})$ & $26.3 \pm 2.3^{\mathrm{a}}$ & $24.9 \pm 2.8^{\mathrm{a}}$ & $3.21 \pm 0.63^{\mathrm{a}}$ & $2.79 \pm 0.79^{\mathrm{a}}$ \\
\hline Hyperglycemic-pioglitazone (HP) & $27.2 \pm 0.3^{\mathrm{a}}$ & $23.9 \pm 1.8^{\mathrm{a}}$ & $2.31 \pm 0.15$ & $2.01 \pm 0.34^{\mathrm{a}}$ \\
\hline Hyperglycemic-repaglinide (HR) & $26.4 \pm 1.2^{\mathrm{a}}$ & $24.0 \pm 2.3^{\mathrm{a}}$ & $2.32 \pm 0.15^{\mathrm{a}}$ & $2.02 \pm 0.04^{\mathrm{a}}$ \\
\hline
\end{tabular}

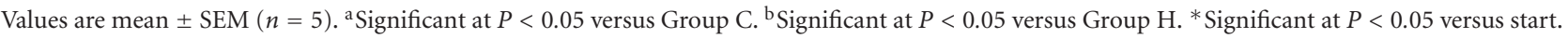

stress [35]. In our previous studies concerning heart, lung, and testis, repaglinide significantly affected nitrotyrosine and LPO levels but did not affect $\mathrm{NO}_{2}$ and PCG levels [31, 32]. It was confirmed in the present study by the lack of any effect on PCG, AOPP, and $\mathrm{NO}_{2}$.

What is important in the present study is that pioglitazone and repaglinide did not significantly affect glucose concentration in our hyperglycemic animals. After alloxan injection, these animals preserved insulin secretion but its amount was very low because of destruction of many B cells by alloxan. Therefore, repaglinide could not stimulate its secretion in sufficient way and pioglitazone failed to affect its sensitivity (Table 2). This lack of antihyperglycemic activity was expected and used by us to differentiate, at least in part, some direct antioxidative/antinitrosative effects of the drugs from effects mediated via increased insulin action. When animals with type 2 diabetes were used, these two kinds of effects could not be separated.

\section{Conclusions}

In aqueous humor of our hyperglycemic animals, the decreased AA, GSH, and TAS as well as increased $\mathrm{LPO}, \mathrm{NO}_{2}$, PCG, and AOPP were observed confirming the exposition of ocular structures on oxidative/nitrosative stress. It was observed that correlations between AOPP and other factors were more expressive than the same correlations for PCG. We concluded that AOPP which was easy to obtain, corresponded better than PCG to other examined parameters. In addition, antioxidative/antinitrosative properties of pioglitazone and repaglinide were compared. The results obtained in the present study confirm that pioglitazone and repaglinide differ significantly in their ability to ameliorate the examined markers of oxidative/nitrosative stress in aqueous humor, especially in respect to protein modifications. It cannot be excluded that $\mathrm{K}_{\mathrm{ATP}}$ channel blockers like repaglinide may affect oxidative/nitrosative stress but PPAR $\gamma$ agonists like pioglitazone seem to act more comprehensively which was confirmed independently on their action oh hyperglycemia.

\section{References}

[1] P. Geraldine, B. B. Sneha, R. Elanchezhian et al., "Prevention of selenite-induced cataractogenesis by acetyl-L-carnitine: an experimental study," Experimental Eye Research, vol. 83, no. 6, pp. 1340-1349, 2006.

[2] I. Grattagliano, G. Vendemiale, F. Boscia, T. Micelli-Ferrari, L. Cardia, and E. Altomare, "Oxidative retinal products and ocular damages in diabetic patients," Free Radical Biology and Medicine, vol. 25, no. 3, pp. 369-372, 1998.

[3] S. E. Ohia, C. A. Opere, and A. M. LeDay, "Pharmacological consequences of oxidative stress in ocular tissues," Mutation Research, vol. 579, no. 1-2, pp. 22-36, 2005.

[4] N. Ahmed, R. Babaei-Jadidi, and S. K. Howell, "Degradation products of proteins damaged by glycation, oxidation and nitration in clinical type 1 diabetes," Diabetologia, vol. 48, no. 8, pp. 1590-1603, 2005.

[5] R. A. Kowluru, "Diabetes-induced elevations in retinal oxidative stress, protein kinase C and nitric oxide are interrelated," Acta Diabetologica, vol. 38, no. 4, pp. 179-185, 2001.

[6] N. Toda and M. Nakanishi-Toda, "Nitric oxide: ocular blood flow, glaucoma, and diabetic retinopathy," Progress in Retinal and Eye Research, vol. 26, no. 3, pp. 205-238, 2007.

[7] X. M. Zhang, K. Ohishi, and T. Hiramitsu, "Microdialysis measurement of ascorbic acid in rabbit vitreous after photodynamic reaction," Experimental Eye Research, vol. 73, no. 3, pp. 303-309, 2001.

[8] B. Anderstam, A. C. Bragfors-Helin, A. Valli, P. Stenvinkel, B. Lindholm, and M. E. Suliman, "Modification of the oxidative stress biomarker AOPP assay: application in uremic samples," Clinica Chimica Acta, vol. 393, no. 2, pp. 114-118, 2008.

[9] H. Kaneda, J. Taguchi, K. Ogasawara, T. Aizawa, and M. Ohno, "Increased level of advanced oxidation protein products in patients with coronary artery disease," Atherosclerosis, vol. 162, no. 1, pp. 221-225, 2002.

[10] A. Piwowar, M. Knapik-Kordecka, and M. Warwas, "AOPP and its relations with selected markers of oxidative/antioxidative system in type 2 diabetes mellitus," Diabetes Research and Clinical Practice, vol. 77, no. 2, pp. 188-192, 2007.

[11] M. Stefek, Z. Kyselova, L. Rackova, and L. Krizanova, “Oxidative modification of rat eye lens proteins by peroxyl radicals in vitro: protection by the chain-breaking antioxidants stobadine and trolox," Biochimica et Biophysica Acta, vol. 1741, no. 1-2, pp. 183-190, 2005.

[12] S. A. Madsen-Bouterse and R. A. Kowluru, "Oxidative stress and diabetic retinopathy: pathophysiological mechanisms and treatment perspectives," Reviews in Endocrine and Metabolic Disorders, vol. 9, no. 4, pp. 315-327, 2008.

[13] I. Inoue, S. Goto, T. Matsunaga et al., "The ligands/activators for peroxisome proliferator-activated receptor $\alpha(\operatorname{PPAR} \alpha)$ and PPAR $\gamma$ increase $\mathrm{Cu}^{+2}, \mathrm{Zn}^{+2}$-superoxide dismutase and decrease 
$\mathrm{p} 22^{\text {phox }}$ message expression in primary endothelial cells," Metabolism, vol. 50, no. 1, pp. 3-11, 2001.

[14] J. B. Majithiya, A. N. Paramar, and R. Balaraman, "Pioglitazone, a PPAR $\gamma$ agonist, restores endothelial function in aorta of streptozotocin-induced diabetic rats," Cardiovascular Research, vol. 66, no. 1, pp. 150-161, 2005.

[15] Y. Li, L. Xu, J. Shen et al., "Effects of short-term therapy with different insulin secretagogues on glucose metabolism, lipid parameters and oxidative stress in newly diagnosed type 2 diabetes mellitus," Diabetes Research and Clinical Practice, vol. 88, no. 1, pp. 42-47, 2010.

[16] D. Manzella, A. M. Abbatecola, R. Grella, and G. Paolisso, "Repaglinide administration improves brachial reactivity in type 2 diabetic patients," Diabetes Care, vol. 28, no. 2, pp. 366371, 2005.

[17] T. Tankova, D. Koev, L. Dakovska, and G. Kirilov, "The effect of repaglinide on insulin secretion and oxidative stress in type 2 diabetic patients," Diabetes Research and Clinical Practice, vol. 59, no. 1, pp. 43-49, 2003.

[18] A. Kyaw, "A simple colorimetric method for ascorbic acid determination in blood plasma," Clinica Chimica Acta, vol. 86, no. 2, pp. 153-157, 1978.

[19] O. H. Lowry, N. J. Rosenbrough, A. L. Farr, and R. J. Randall, "Protein measurement with the Folin phenol reagent," The Journal of Biological Chemistry, vol. 193, no. 1, pp. 265-275, 1951.

[20] S. M. Ferreira, S. F. Lerner, R. Brunzini, P. A. Evelson, and S. F. Llesuy, "Oxidative stress markers in aqueous humor of glaucoma patients," American Journal of Ophthalmology, vol. 137 , no. 1, pp. 62-69, 2004

[21] C. Livingstone and J. Davis, "Targeting therapeutics against glutathione depletion in diabetes and its complications," The British Journal of Diabetes and Vascular Disease, vol. 7, no. 6, pp. 258-265, 2007.

[22] T. Fujii, R. Hamaoka, J. Fujii, and N. Taniguchi, "Redox capacity of cells affects inactivation of glutathione reductase by nitrosative stress," Archives of Biochemistry and Biophysics, vol. 378, no. 1, pp. 123-130, 2000.

[23] M. P. Cohen, E. Hud, E. Shea, and C. W. Shearman, "Vitreous fluid of $d b / d b$ mice exhibits alterations in angiogenic and metabolic factors consistent with early diabetic retinopathy," Ophthalmic Research, vol. 40, no. 1, pp. 5-9, 2008.

[24] M. Aslan, A. Cort, and I. Yucel, "Oxidative and nitrative stress markers in glaucoma," Free Radical Biology and Medicine, vol. 45, no. 4, pp. 367-376, 2008.

[25] R. L. Levine, D. Garland, C. N. Oliver et al., "Determination of carbonyl content in oxidatively modified proteins," Methods in Enzymology, vol. 186, pp. 464-478, 1990.

[26] T. Nguyen-Khoa, Z. A. Massy, J. P. de Bandt et al., "Oxidative stress and haemodialysis: role of inflammation and duration of dialysis treatment," Nephrology Dialysis Transplantation, vol. 16, no. 2, pp. 335-340, 2001.

[27] M. Kalousova, J. Skrha, and T. Zima, "Advanced glycation endproducts and advanced oxidation protein products in patients with diabetes mellitus," Physiological Research, vol. 51, no. 6, pp. 597-604, 2002.

[28] T. Shiojiri, K. Wada, A. Nakajima et al., "PPAR $\gamma$ ligands inhibit nitrotyrosine formation and inflammatory mediator expressions in adjuvant-induced rheumatoid arthritis mice," European Journal of Pharmacology, vol. 448, no. 2-3, pp. 231238, 2002.

[29] B. Sung, S. Park, B. P. Yu, and H. Y. Chung, "Amelioration of age-related inflammation and oxidative stress by PPAR $\gamma$ activator: Suppression of NF- $\kappa$ B by 2,4-thiazolidinedione," Experimental Gerontology, vol. 41, no. 6, pp. 590-599, 2006.

[30] L. Tao, H. Liu, E. Gao et al., "Antioxidative, antinitrative, and vasculoprotective effects of a peroxisome proliferatoractivated receptor- $\gamma$ agonist in hypercholesterolemia," Circulation, vol. 108, no. 22, pp. 2805-2811, 2003.

[31] A. Gumieniczek, Ł. Komsta, and M. R. Chehab, "Effects of two oral antidiabetics, pioglitazone and repaglinide, on aconitase inactivation, inflammation and oxidative/nitrosative stress in tissues under alloxan-induced hyperglycemia," European Journal of Pharmacology, vol. 659, no. 1, pp. 89-93, 2011.

[32] A. Gumieniczek, M. Krzywdzińska, and M. Nowak, "Modulation of nitrosative/oxidative stress in the lung of hyperglycemic rabbits by two antidiabetics, pioglitazone and repaglinide," Experimental Lung Research, vol. 35, no. 5, pp. 371-379, 2009.

[33] B. Gross and B. Staels, "PPAR agonists: multimodal drugs for the treatment of type-2 diabetes," Best Practice and Research in Clinical Endocrinology and Metabolism, vol. 21, no. 4, pp. 687$710,2007$.

[34] R. Assaloni, R. da Ros, L. Quagliaro et al., "Effects of S21403 (mitiglinide) on postprandial generation of oxidative stress and inflammation in type 2 diabetic patients," Diabetologia, vol. 48, no. 9, pp. 1919-1924, 2005.

[35] J. E. da Silva-Santos, M. C. Santos-Silva, F. Cunha, and J. Assreuy, "The role of ATP-sensitive potassium channels in neutrophil migration and plasma exudation," The Journal of Pharmacology and Experimental Therapeutics, vol. 300, no. 3, pp. 946-951, 2002. 


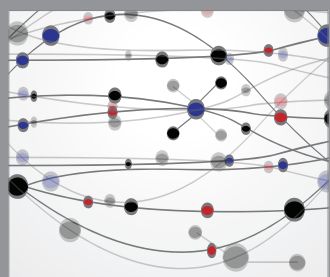

The Scientific World Journal
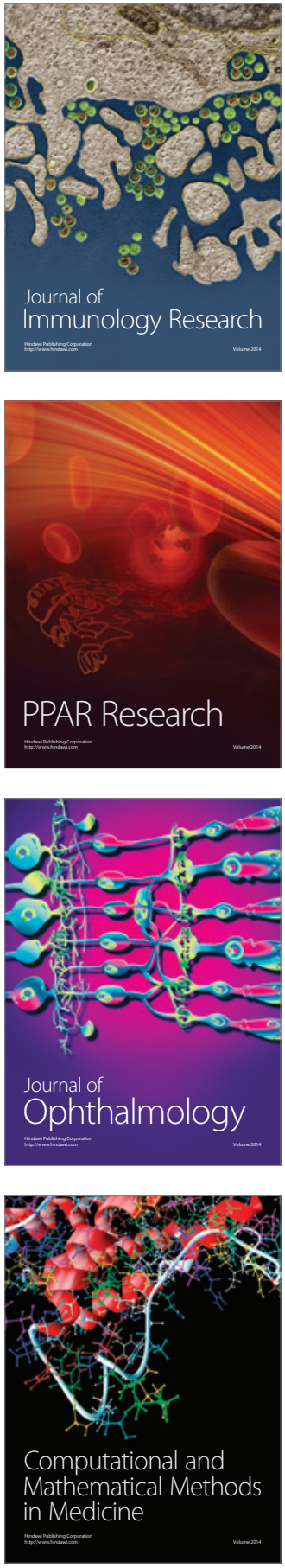

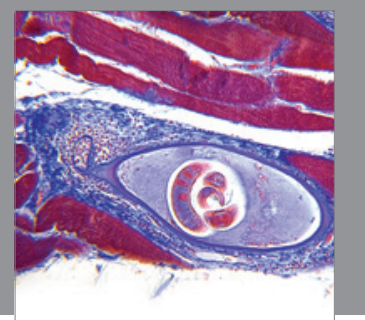

Gastroenterology

Research and Practice
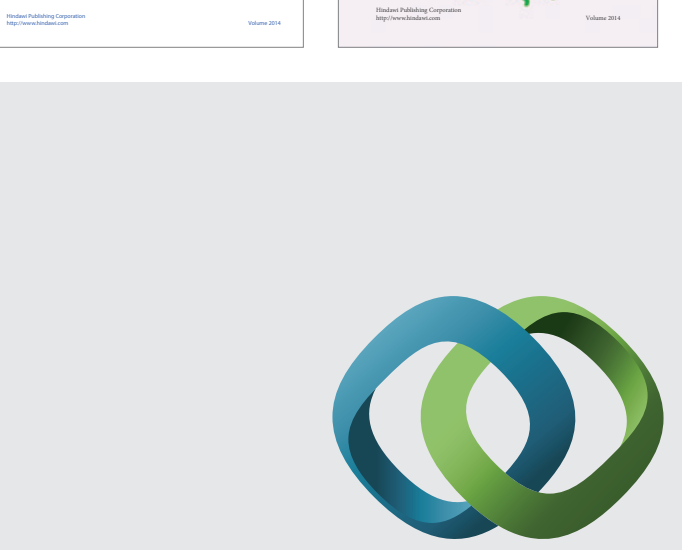

\section{Hindawi}

Submit your manuscripts at

http://www.hindawi.com
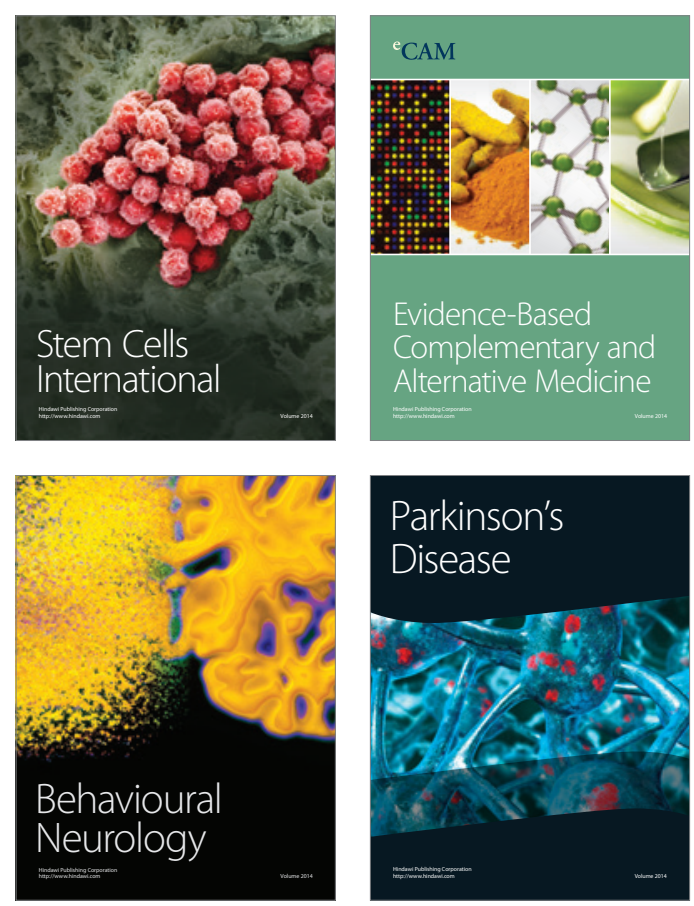

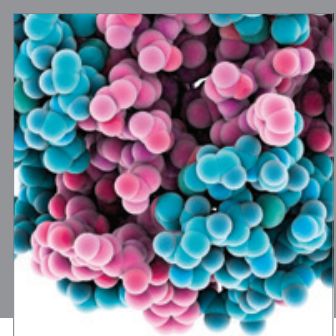

Journal of
Diabetes Research

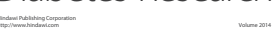

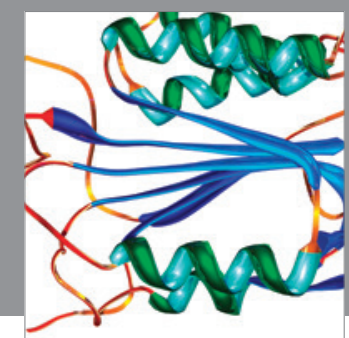

Disease Markers
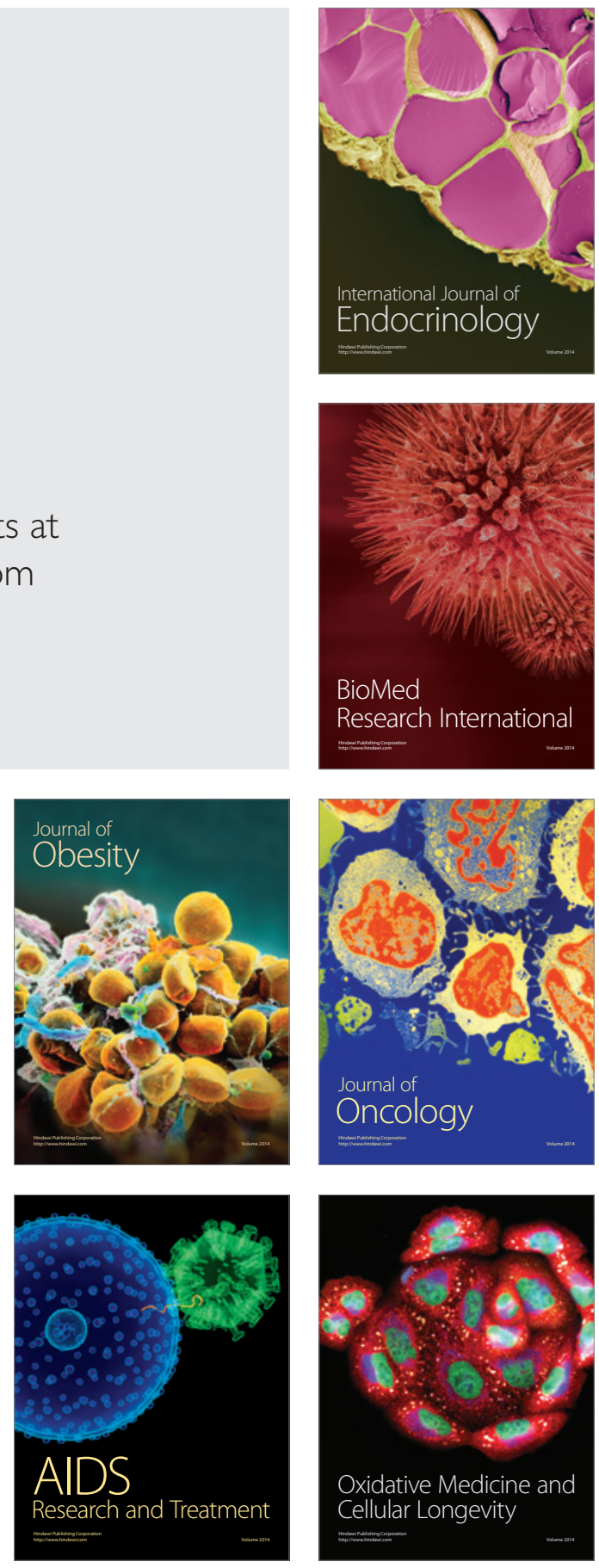